\title{
Protective effects of apigenin against 1-methyl-4-phenylpyridinium ion-induced neurotoxicity in PC12 cells
}

\author{
WEIHAI LIU ${ }^{1,2^{*}}$, SONGZHI KONG ${ }^{4 *}$, QINGFENG XIE ${ }^{3}$, JIYAN SU$^{2}$, WENJIE LI $^{2}$,

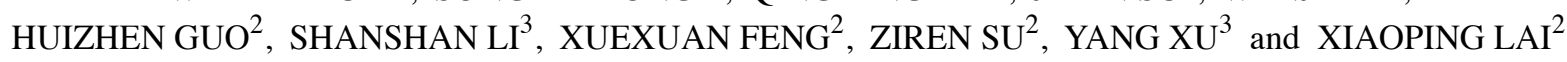 \\ ${ }^{1}$ Guangdong Food and Drug Vocational College, Guangzhou, Guangdong 510520; ${ }^{2}$ School of Chinese Materia Medica, \\ Guangzhou University of Chinese Medicine, Guangzhou, Guangdong 510006; ${ }^{3}$ Guangdong Provincial Hospital \\ of Traditional Chinese Medicine, Guangzhou, Guangdong 510120; ${ }^{4}$ College of Science, \\ Guangdong Ocean University, Zhanjiang, Guangdong 524088, P.R. China
}

Received July 13, 2014; Accepted December 4, 2014

DOI: $10.3892 / \mathrm{ijmm} .2014 .2056$

\begin{abstract}
Parkinson's disease is recognized as the second most common neurodegenerative disorder after Alzheimer's disease, characterized by the loss of dopominergic neurons in the substantia nigra pars compacta and can be experimentally mimicked by the use of the neurotoxin, 1-methyl-4-phenylpyridinium ion $\left(\mathrm{MPP}^{+}\right)$, in in vitro models. In this study, we investigated the potential protective effects of apigenin (AP), galangin and genkwanin, naturally occurring plant flavonoids, on the $\mathrm{MPP}^{+}$-induced cytotoxicity in cultured rat adrenal pheochromocytoma cells (PC12 cells). The PC12 cells were pre-treated with various concentrations of the test compounds for $4 \mathrm{~h}$, followed by the challenge with $1,000 \mu \mathrm{M} \mathrm{MPP}^{+}$for $48 \mathrm{~h}$. We found that only pre-treatment with $\operatorname{AP}(3,6$ and $12 \mu \mathrm{M})$ before injury significantly increased cell viability, decreased the release of lactate dehydrogenase, reduced the level of intra-
\end{abstract}

Correspondence to: Professor Xiaoping Lai, School of Chinese Materia Medica, Guangzhou University of Chinese Medicine, 232 Waihuandong Road, Guangzhou Higher Education Mega Center, Guangzhou, Guangdong 510006, P.R. China

E-mail:1xp88@gzucm.edu.cn

Professor Yang Xu, Guangdong Provincial Hospital of Traditional Chinese Medicine, 111 Dade Road, Yuexiu District, Guangzhou, Guangdong 510120, P.R. China

E-mail: yangxu@ucsd.edu

\section{${ }^{*}$ Contributed equally}

Abbreviations: PD, Parkinson's disease; ROS, reactive oxygen species; MMP, mitochondrial membrane potential; $\mathrm{MPP}^{+}$, 1-methyl4-phenylpyridinium ion; PI, propidium iodide; AP, apigenin; GA, galangin; GE, genkwanin; DCFH-DA, 2',7'-dichlorofluorescin diacetate; LDH, lactate dehydrogenase; JC-1, 5,5',6,6'-tetrachloro-1,1',3,3'-tetraethyl benzimidazolyl carbocyanine iodide

Key words: apigenin, Parkinson's disease, 1-methyl-4-phenylpyridinium ion, rat pheochromocytoma cells, neuroprotection cellular reactive oxygen species and elevated mitochondrial membrane potential in the $\mathrm{MPP}^{+}$-treated PC12 cells. In addition, AP markedly suppressed the increased rate of apoptosis and the reduced $\mathrm{Bcl}-2 / \mathrm{Bax}$ ratio induced by $\mathrm{MPP}^{+}$in the $\mathrm{PC} 12$ cells. Taken together, the findings of this study demonstrate that AP exerts neuroprotective effects against $\mathrm{MPP}^{+}$-induced neurotoxicity in PC12 cells, at least in part, through the inhibition of oxidative damage and the suppression of apoptosis through the mitochondrial pathway.

\section{Introduction}

It is well recognized that Parkinson's disease (PD), one of the most common neurodegenerative movement disorders, is characterized by the selective degeneration of dopaminergic neurons in the nigrostriatal system (1). Recent statistics show that PD affects approximately $2 \%$ of the population over the age of 60 and the incidence is expected to rise dramatically in the next 25 years with the extension of life expectancy by improved health care (2). Although the detailed mechanisms responsible for PD are still under investigation (3), extensive research over the last several decades has indicated that mitochondrial dysfunction and oxidative stress resulting from the excessive production of reactive oxygen species (ROS) play crucial roles in the pathogenesis of PD $(4,5)$. Oxidative stress induced by ROS induces the opening of the mitochondrial permeability transition pore and the dissipation of mitochondrial membrane potential (MMP) (6) and, subsequently, apoptotic activators are released from the mitochondria (7), finally resulting in the apoptosis of dopaminergic neurons observed in PD (8).

Advances in our understanding of dopaminergic neuronal apoptosis in PD have been achieved by studies on Parkinsonism induced by 1-methyl-4-phenyl-1,2,3,6-tetrahydropyridine (MPTP) and 1-methyl-4-phenylpyridinium ion $\left(\mathrm{MPP}^{+}\right)(9,10)$. Moreover, pheochromocytoma cells (PC12 cells), derived from a clonal rat pheochromocytoma cell line, have been widely used as cellular models of PD, as these cells share characteristics with midbrain dopaminergic neurons $(11,12)$. In addition, previous studies have demonstrated that $\mathrm{MPP}^{+}$-induced cytotoxicity in PC12 cells, which induces apoptotic characteristics accompa- 
nied by mitochondrial dysfunction and oxidative stress, is a classic cellular model of PD $(13,14)$. Therefore, in this study, we investigated the effects of three plant flavonoids on cytotoxicity in $\mathrm{MPP}^{+}$-treated PC12 cells to determine whether they may be of preventive or potential therapeutic value in $\mathrm{PD}$.

Naturally occurring plant-derived flavonoids have been suggested to play a role in protecting the central nervous system against oxidative and excitotoxic stress, although the mechanisms of action require further study (15). In this study, using $\mathrm{MPP}^{+}$as the oxidative insult in PC12 cells, we investigated the mechanisms responsible for neurotoxicity and attempted to identify the possible sites of action of three of the most potent protective flavonoids, apigenin (AP), galangin (GA) and genkwanin (GE) (the chemical structures are shown in Fig. 1). AP (4',5,7-trihydroxyflavone), GA (3,5,7-trihydroxyflavone) and GE (4',5-dihydroxy-7-methoxyflavone), which are very similar in structure, have been reported to possess a number of similar biological activities, including antioxidant/free radical scavenging activity, antitumor effects and anti-inflammatory activity (16-19). Furthermore, AP has been shown to inhibit $\mathrm{A} \beta$-mediated oxidative damage in nerve cells and in animal models of Alzheimer's disease $(20,21)$. Additionally, several antioxidants and free radical scavengers, including luteolin (22), morin (23) and myricetin (24), which also have a similar chemical structure to that of these three flavonoid compounds, have been reported to attenuate the oxidative toxicity induced by $\mathrm{MPP}^{+}$. However, to the best of our knowlege, no study has been published to date on the protective effects of these three flavonoid compounds against $\mathrm{MPP}^{+}$-induced toxicity in vivo or in vitro. Therefore, in the present study, we aimed to investigate whether these compounds exert protective effects against $\mathrm{MPP}^{+}$-induced neurotoxicity in $\mathrm{PC} 12$ cells and to explore the underlying molecular mechanisms of these neuroprotective effects.

\section{Materials and methods}

Chemicals and reagents. AP, GA and GE, purchased from Sigma-Aldrich (St. Louis, MO, USA), were dissolved in dimethyl sulfoxide (DMSO) $(<0.1 \%)$ and diluted with serum-free medium prior to each experiment. $\mathrm{MPP}^{+}$and methylthiazolyldiphenyl-tetrazolium bromide (MTT) were also purchased from Sigma-Aldrich. 2',7'-Dichlorofluorescin diacetate (DCFH-DA) was obtained from Invitrogen Life Technologies (Carlsbad, CA, USA). Dulbecco's modified Eagle's medium (DMEM), fetal bovine serum, penicillin and streptomycin were purchased from Gibco (Grand Island, NY, USA). All other reagents and chemicals used in the study were of analytical grade.

Cell culture and drug treatment. The PC12 cells, obtained from the American Type Culture Collection (ATCC, Rockville, MD, USA), were routinely cultured in DMEM supplemented with heat-inactivated horse serum $(5 \%, \mathrm{v} / \mathrm{v})$, heat-inactivated fetal calf serum $(5 \%, \mathrm{v} / \mathrm{v})$, penicillin $(100 \mathrm{IU} / \mathrm{ml})$ and streptomycin $(100 \mu \mathrm{g} / \mathrm{ml})$ at $37^{\circ} \mathrm{C}$ in a humidified atmosphere of $5 \%$ $\mathrm{CO}_{2} / 95 \%$ air. The culture medium was changed every 2 days. In all the experiments, apart from the assessment of cell viability, the cells were incubated for $24 \mathrm{~h}$ and were then treated for $4 \mathrm{~h}$ with or without various concentrations of AP, GA and GE (3,<smiles>O=c1cc(-c2ccc(O)cc2)oc2cc(O)cc(O)c12</smiles><smiles>COc1cc(O)c2c(=O)cc(-c3ccc(O)cc3)oc2c1</smiles>

Figure 1. Chemical structures of apigenin, galangin and genkwanin.

6 and $12 \mu \mathrm{M}$ ), prior to the addition of $\mathrm{MPP}^{+}$(final concentration, $1,000 \mu \mathrm{M}$ ) for an additional $48 \mathrm{~h}$. The control cells were treated in the same manner without the addition of the test compounds and $\mathrm{MPP}^{+}$to the free serum culture medium. All experiments were repeated at least 3 times for each treatment condition in each experiment.

MTT assay. Cell survival was quantified by the colorimetric MTT assay using a previously described protocol (14). Briefly, the PC12 cells were seeded in 96-well culture plates at a density of $2 \times 10^{4}$ cells/well; following treatment with the drugs, MTT solution was added to the cell cultures at a final concentration of $1 \mathrm{mg} / \mathrm{ml}$ followed by incubation for a further $4 \mathrm{~h}$ at $37^{\circ} \mathrm{C}$. The supernatant was carefully aspirated and $150 \mu 1$ of DMSO were added to dissolve the formazan crystals. The 96-well microplate was then transferred to a microplate reader (BMG Labtech, Offenbury, Germany) and the absorbance was read at $570 \mathrm{~nm}$. Cell viability was expressed as the percentage of the untreated controls.

Lactate dehydrogenase (LDH) activity assay. Cytotoxicity was quantitatively assessed by measuring the activity of LDH released from the damaged cells into the culture medium (25). The PC12 cells were seeded in 96-well culture plates at a density of $2 \times 10^{4}$ cells/well and treated according to the procedures as described above. At the end of the treatments, the medium was collected for the measurement of the extracellular $\mathrm{LDH}$ level; the cells were then treated with $0.5 \%$ Triton X-100, after being centrifuged at $10,000 \mathrm{x} \mathrm{g}$ and the supernatant was used for the measurement of the intracellular LDH level by spectrophotometrical determination at $440 \mathrm{~nm}$ following the procedures provided in the assay kits (Nanjing Jiancheng Bioengineering Institute, Nanjing, China). LDH release was expressed as the percentage of the total LDH activity (LDH in the medium $+\mathrm{LDH}$ in the cells), according to the following equation: $\mathrm{LDH}$ release $(\%)=(\mathrm{LDH}$ activity in the medium $/$ total LDH activity) x100. Cultures under normal conditions (control group) represent the basal LDH release.

Measurement of intracellular ROS production. Intracellular ROS production was measured using the intracellular peroxide-sensitive fluorescent probe, DCFH-DA, as previously 
described (25). Briefly, the PC12 cells were seeded in 96-well black culture plates at a density of $2 \times 10^{4}$ cells/well and treated according to the procedures as described above. Following treatment with $\mathrm{MPP}^{+}$and the drugs, the cells were washed twice with D-Hank's solution and incubated with DCFH-DA at a final concentration of $10 \mu \mathrm{M}$ for $30 \mathrm{~min}$ at $37^{\circ} \mathrm{C}$ in dark. After the cells were washed twice with D-Hank's solution to remove the extracellular DCFH-DA, the fluorescence intensity was measured using a fluorescence microplate reader (Tecan, Groedig, Austria) at an excitation wavelength of $485 \mathrm{~nm}$ and an emission wavelength of $538 \mathrm{~nm}$. The measured fluorescence values were expressed as the fold changes relative to the control group.

Additionally, the PC12 cells were seeded in 6-well culture plates at a density of $1 \times 10^{6}$ cells/well. At the end of the drug treatment, the cells were washed twice with D-Hank's solution and incubated with DCFH-DA (final concentration, $10 \mu \mathrm{M}$ ) for $30 \mathrm{~min}$ at $37^{\circ} \mathrm{C}$ in the dark. Changes in ROS production were then assessed using a fluorescence microscope (Olympus, Tokyo, Japan).

Measurement of MMP. A JC-1 kit (Beyotime, Haimen, China) was used to measure the mitochondrial depolarization in the PC12 cells according to the manufacturer's instructions. 5,5',6,6'-tetrachloro-1,1',3,3'-tetraethyl benzimidazolyl carbocyanine iodide (JC-1) is a cationic dye for detecting MMP changes, where mitochondrial depolarization is indicated by an increase in the green/red fluorescence intensity ratio. In the mitochondria of healthy cells, JC-1 forms aggregates and fluoresces red. When the MMP collapses, the cationic dye remains in the cytoplasm as green fluorescence, its monomeric form. Briefly, on the one hand, PC12 cells were seeded in 96-well black culture plates at a density of $2 \times 10^{4}$ cells/well. At the end of the drug treatment, the cells were washed twice with D-Hank's solution and incubated with JC-1 reagent (final concentration, $10 \mu \mathrm{g} / \mathrm{ml}$ ) for $20 \mathrm{~min}$ at $37^{\circ} \mathrm{C}$ in the dark. Subsequently, the green (excitation, 490; emission, $530 \mathrm{~nm}$ ) and red (excitation, 525; emission, $590 \mathrm{~nm}$ ) fluorescence were measured using a fluorescence plate reader (Tecan). The measured green/red fluorescence ratios were expressed as fold changes relative to the control group.

On the other hand, the PC12 cells were seeded in 6-well culture plates at a density of $1 \times 10^{6}$ cells/well. At the end of the drug treatment, the cells were washed twice with D-Hank's solution and incubated with JC-1 (final concentration, $10 \mu \mathrm{g} / \mathrm{ml}$ ) for $20 \mathrm{~min}$ at $37^{\circ} \mathrm{C}$ in dark. Changes in MMP were assessed using a fluorescence microscope (Olympus).

Flow cytometric analysis of apoptosis. The apoptotic rate was measured by flow cytometry according to the protocol provided with the Annexin V-FITC/PI kit (Sigma-Aldrich). Briefly, the $\mathrm{PC} 12$ cells were seeded in 6-well culture plates at a density of $1 \times 10^{6}$ cells/well. At the end of the drug treatment, the cells were harvested by centrifugation at 1,000 x g, washed twice with ice-cold phosphate-buffered saline (PBS) and resuspended in binding buffer at a concentration of $1 \times 10^{6}$ cells $/ \mathrm{ml}$. A total of $5 \mu \mathrm{l}$ of $20 \mu \mathrm{g} / \mathrm{ml}$ Annexin V-FITC and $50 \mu \mathrm{g} / \mathrm{ml}$ propidium iodide (PI) were added and the tube was incubated for $30 \mathrm{~min}$ in the dark. The quantitative analysis of apoptosis was carried out using a flow cytometer (BD Biosciences, San Jose, CA, USA).
Quadrants were positioned on Annexin V-FITC/PI dot plots, allowing living cells (Annexin V-FITC-/PI-), early/primary apoptotic cells (Annexin $\mathrm{V}-\mathrm{FITC}^{+} / \mathrm{PI}^{-}$), late/secondary apoptotic cells (Annexin $\mathrm{V}-\mathrm{FITC}^{+} / \mathrm{PI}^{+}$) and necrotic cells (Annexin V-FITC $-/ \mathrm{PI}^{+}$) to be distinguished (26). Data were analyzed using CellQuest ${ }^{\mathrm{TM}}$ software (BD Biosciences).

Western blot analysis. Western blo analysis was performed to investigate the changes in the protein levels of Bcl-2 and Bax. The PC12 cells were seeded onto $100-\mathrm{mm}$ dishes at $5 \times 10^{6}$ cells/dish and allowed to grow until confluent. The cells were then washed twice with ice-cold D-Hank's solution after drug treatment and lysed using protein lysis buffer. The lysates were collected by scraping from the plates and then centrifugation at $13,000 \mathrm{x} g$ at $4^{\circ} \mathrm{C}$ for $15 \mathrm{~min}$. The supernatant was separated and stored at $-80^{\circ} \mathrm{C}$ until use.

Western blot analysis was performed according to a procedure described previously (27). Briefly, protein samples were electrophoresed by SDS-PAGE for $2 \mathrm{~h}$ at $80 \mathrm{~V}$ and then transferred onto polyvinylidene fluoride membranes for $40 \mathrm{~min}$ at $200 \mathrm{~mA}$. The blots were blocked for $2 \mathrm{~h}$ at room temperature in fresh blocking buffer $(0.1 \%$ Tween-20 in Tris-buffered saline, $\mathrm{pH} 7.4$, containing 5\% non-fat dried milk) and subsequently incubated at $4{ }^{\circ} \mathrm{C}$ overnight with primary antibodies against Bcl-2 (1:300; Santa Cruz Biotechnology, Inc., Santa Cruz, CA, USA), Bax (1:200; Santa Cruz Biotechnology, Inc.) or GAPDH (1:500; Santa Cruz Biotechnology, Inc.) in blocking solution. Subsequently, the membranes were washed with TBS-T (Tris-buffer saline containing $0.1 \%$ Tween-20) 3 times and incubated with horseradish peroxidase-conjugated secondary antibody at 1:5,000 in PBS with 5\% non-fat dry milk at room temperature for $1 \mathrm{~h}$. To verify the equal loading of samples, the membranes were incubated with monoclonal antibody GAPDH, followed by a horseradish peroxidase-conjugated goat anti-mouse IgG. The membrane again was washed with TBS-T 3 times and finally, the protein bands were visualized using ECL western blotting detection reagents (Amersham Biosciences, Buckinghamshire, UK). The intensity of each band was analyzed using Image $\mathrm{J}$ software (NIH Image; National Institutes of Health, Bethesda, MD, USA).

Statistical analysis. All quantitative data are presented as the means \pm standard error of the mean (SEM). The changes in variable parameters between the treated groups and the control group were analyzed by one-way ANOVA followed by Dunnett's test as a post hoc comparison. A value of $\mathrm{p}<0.05$ was considered to indicate a statistically significant difference in all cases.

\section{Results}

Effects of the test compounds on $M P P^{+}$-induced cytotoxicity in PC12 cells. To investigate the effects of $\mathrm{MPP}^{+}$on PC12 cells, we exposed the cells to a range of concentrations of $\mathrm{MPP}^{+}$ (250-1,500 $\mu \mathrm{M})$ for various periods of time (24, 48 and $72 \mathrm{~h}$ ). There was a concentration- and time-dependent decrease in cell viability following exposure to $\mathrm{MPP}^{+}$(Fig. 2A). The cells exposed to $1,000 \mu \mathrm{M} \mathrm{MPP}^{+}$for $48 \mathrm{~h}$ exhibited $59.5 \%$ of the cell viability observed in the control cells. Therefore, we used 1,000 $\mu \mathrm{M} \mathrm{MPP}^{+}$treatent for $48 \mathrm{~h}$ as the optimal standard 

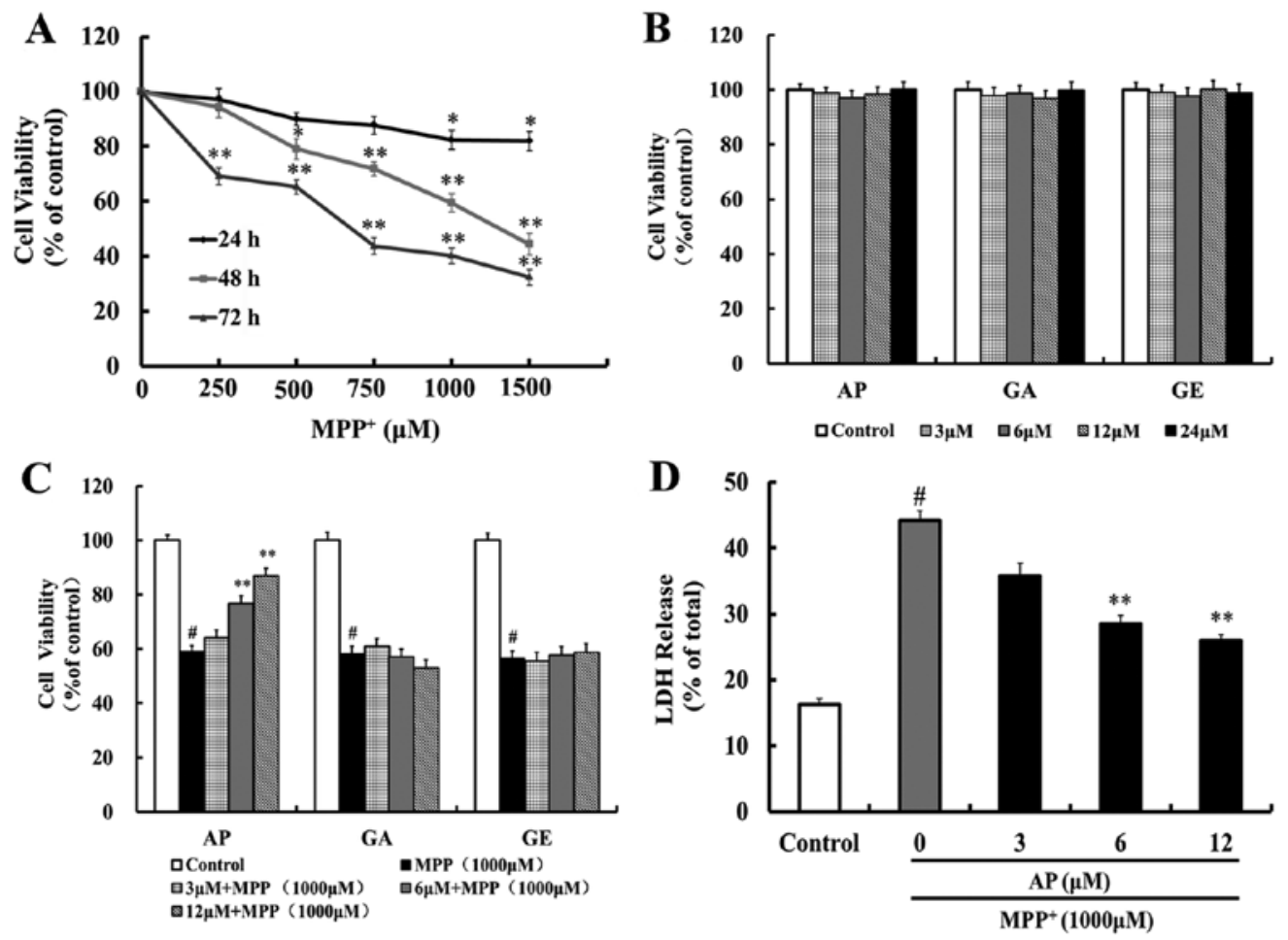

Figure 2. Effects of apigenin (AP), galangin (GA), genkwanin (GE) and 1-methyl-4-phenylpyridinium ion (MPP $)$ on the viability of rat pheochromocytoma cells (PC12 cells). (A) Neurotoxic effects of $\mathrm{MPP}^{+}$on the viability of PC12 cells. (B) Effects of treatment with AP, GA and GE on the viability of PC12 cells. (C) Effects of AP, GA and GE on the viability of PC12 cells subjected to $\mathrm{MPP}^{+}$-induced injury. (D) Effect of AP on MPP+-induced damage in PC12 cells, as indicated by the lactate dehydrogenase $(\mathrm{LDH})$ assay. Data are expressed as the means $\pm \operatorname{SEM}(\mathrm{n}=6) .{ }^{*} \mathrm{p}<0.05,{ }^{\#} \mathrm{p}<0.05$ compared with the control cells; ${ }^{* * *} \mathrm{p}<0.01$ compared with cells exposed to $\mathrm{MPP}^{+}$alone.

concentration and time point for the induction of apoptosis in the subsequent experiments.

We then investigated the neuroprotective effects of the 3 flavonoid compounds (AP, GA and GE). These 3 compounds alone did not have any cytotoxic effects at concentrations ranging between 3-24 $\mu \mathrm{M}$ (Fig. 2B). The PC12 cells were pretreated with these test compounds $(3,6$ and $12 \mu \mathrm{M})$ for $4 \mathrm{~h}$, and then exposed to $1,000 \mu \mathrm{M} \mathrm{MPP}^{+}$for $48 \mathrm{~h}$. MTT assays indicated that pre-treatment with AP $(6$ and $12 \mu \mathrm{M})$ markedly increased the cell viability ( $\mathrm{p}<0.01$ and $\mathrm{p}<0.01$, respectively) as compared with the $\mathrm{MPP}^{+}$group and the survival rate was 76.8 and $86.9 \%$ of the controls, respectively (Fig. 2C). However, pre-treatment with GA and GE (3-12 $\mu \mathrm{M})$ did not increase the cell viability when compared with the $\mathrm{MPP}^{+}$group (Fig. 2C). Therefore, in the subsequent experiments, we focused on the protective effects of AP against $\mathrm{MPP}^{+}$neurotoxicity.

Effect of $A P$ on the $M P P^{+}$-induced release of $L D H$. To further investigate the protective effects of AP, LDH assay, another indicator of cell toxicity, was performed. $\mathrm{LDH}$ is a stable cytoplasmic enzyme present in all cells and is rapidly released into the cell culture supernatant upon damage to he plasma membrane. As shown in Fig. 2D, when the PC12 cells were incubated with $1,000 \mu \mathrm{M} \mathrm{MPP}{ }^{+}$for $48 \mathrm{~h}$, the percentage of LDH being released increased from 16.2 (controls) to $44.1 \%$. Pre-treatment with AP (6 and $12 \mu \mathrm{M})$ significantly attenuated the $\mathrm{MPP}^{+}$-induced release of $\mathrm{LDH}$ to 28.4 and $25.9 \%(\mathrm{p}<0.01$ and $\mathrm{p}<0.01$, respectively), as compared to the $\mathrm{MPP}^{+}$-treated control group.
Effect of AP on the intracellular ROS level in $M P P^{+}$-treated PC12 cells. As shown in Fig. 3, exposure of the PC12 cells to $1,000 \mu \mathrm{M} \mathrm{MPP}{ }^{+}$for $48 \mathrm{~h}$ led to a significant increase in the levels of ROS (2.14-fold increase relative to the control value). However, the overproduction of the intracellular ROS level was markedly inhibited by pre-treatment with AP at concentrations of 3, 6 and $12 \mu \mathrm{M}(\mathrm{p}<0.05, \mathrm{p}<0.01$ and $\mathrm{p}<0.01$, respectively), when compared with the cells cultured with $\mathrm{MPP}^{+}$only.

Effect of AP on MMP in MPP ${ }^{+}$-treated PC12 cells. As shown in Fig. 4, following exposure to $1,000 \mu \mathrm{M} \mathrm{MPP}+$ for $48 \mathrm{~h}$, JC-1 aggregates within the normal mitochondria were dispersed to the monomeric form (green fluorescence) and the ratio of green/red fluorescence intensity was significantly increased ( $\mathrm{p}<0.01$ vs. the control group), suggesting that $\mathrm{MPP}^{+}$induced a significant decrease in MMP. However, pre-treatment with AP $(3,6$ and $12 \mu \mathrm{M})$ markedly prevented the decrease in MMP induced by $\mathrm{MPP}^{+}(\mathrm{p}<0.05, \mathrm{p}<0.01$ and $\mathrm{p}<0.01$, respectively), as compared to the group treated with $\mathrm{MPP}^{+}$alone.

Effect of AP on MPP $P^{+}$-induced apoptosis in PC12 cells. Annexin V-FITC and PI double staining was used to detect apoptosis. As shown in Fig. 5, following exposure to $1,000 \mu \mathrm{M}$ $\mathrm{MPP}^{+}$for $48 \mathrm{~h}$, the percentage of apoptotic cells was significantly increased (43.2\%) in comparison with the control group (5.2\%). However, pre-treatment with AP $(3,6$ and $12 \mu \mathrm{M})$ markedly reduced the cell apoptotic rate $(\mathrm{p}<0.05, \mathrm{p}<0.01$ and $\mathrm{p}<0.01$, respectively) as compared with the $\mathrm{MPP}^{+}$group and the cell apoptotic rate was 33.6, 27.9 and 9.4\%, respectively. 

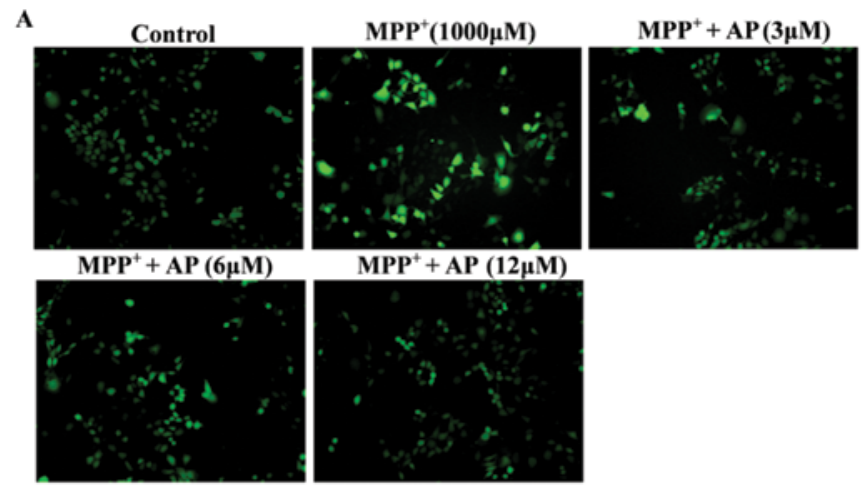

$\mathrm{MPP}^{+}+\mathrm{AP}(12 \mu \mathrm{M})$

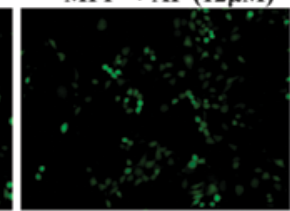

B

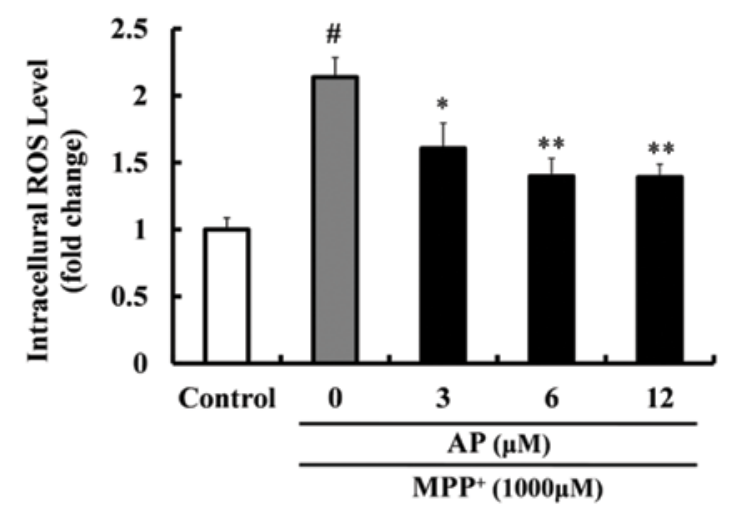

Figure 3. Effect of apigenin (AP) on intracellular reactive oxygen species (ROS) production in 1-methyl-4-phenylpyridinium ion (MPP $)$-treated rat pheochromocytoma cells (PC12 cells). (A) Representative fluorescence images of PC12 cells stained with an intracellular peroxide-sensitive fluorescent probe 2',7'-dichlorofluorescin diacetate (DCFH-DA) (magnification, x200). (B) Quantitative analysis of the fluorescence intensity by using DCFH-DA method. Data are presented as the means \pm SEM of fold changes relative to the controls $(n=3) .{ }^{*} \mathrm{P}<0.01$ compared with the control cells; ${ }^{*} \mathrm{p}<0.05$ and ${ }^{* * *} \mathrm{p}<0.01$ compared with cells exposed to $\mathrm{MPP}^{+}$alone.
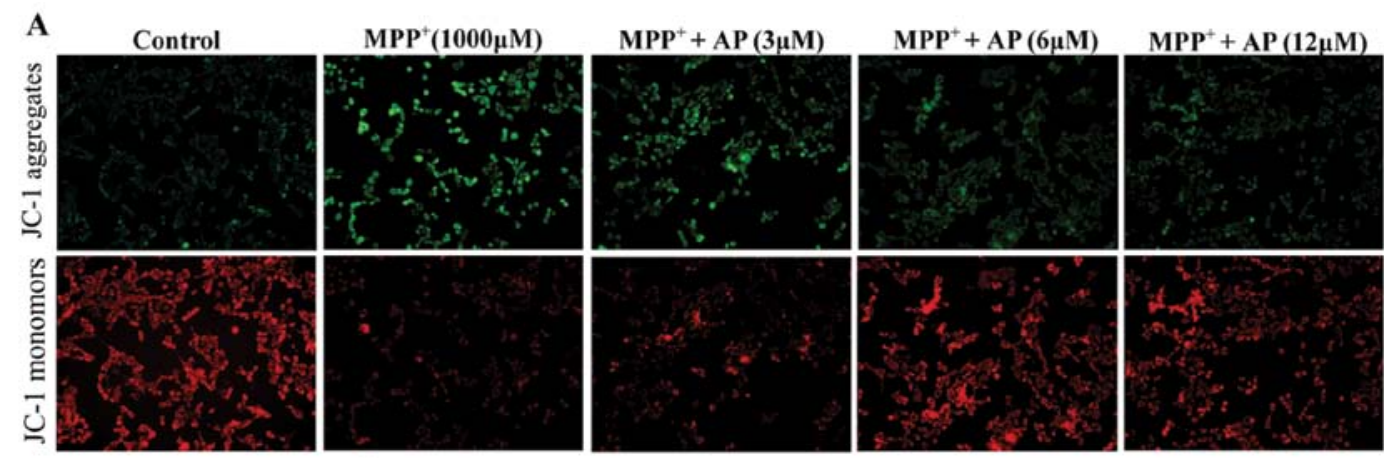

B

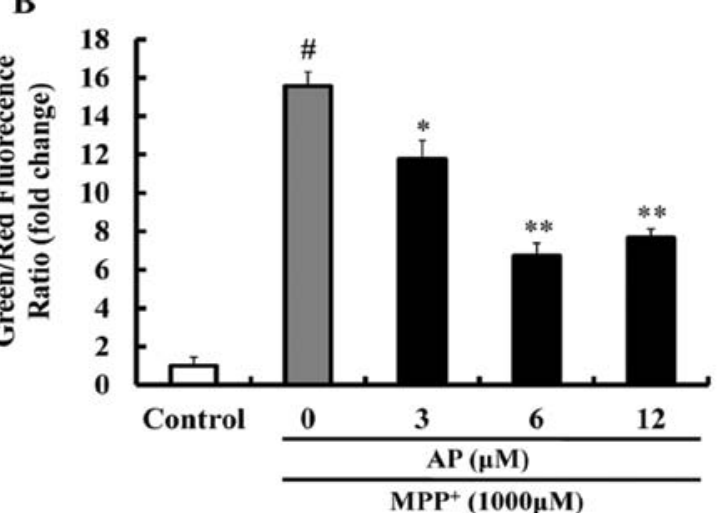

Figure 4. Effect of apigenin (AP) on mitochondrial membrane potential (MMP) in 1-methyl-4-phenylpyridinium ion (MPP')-treated rat pheochromocytoma cells (PC12 cells). (A) Representative fluorescence images of PC12 cells stained with 5,5',6,6'-tetrachloro-1,1',3,3'-tetraethyl benzimidazolyl carbocyanine iodide (JC-1) (magnification, x200). (B) Quantitative analysis of the ratio of green/red fluorescence intensity by using JC-1 method. Data are presented as the means \pm SEM of fold changes relative to the controls $(n=3) .{ }^{*} \mathrm{P}<0.01$ compared with the control cells; ${ }^{*} \mathrm{p}<0.05$ and ${ }^{* *} \mathrm{p}<0.01$ compared with cells exposed to $\mathrm{MPP}^{+}$alone. 

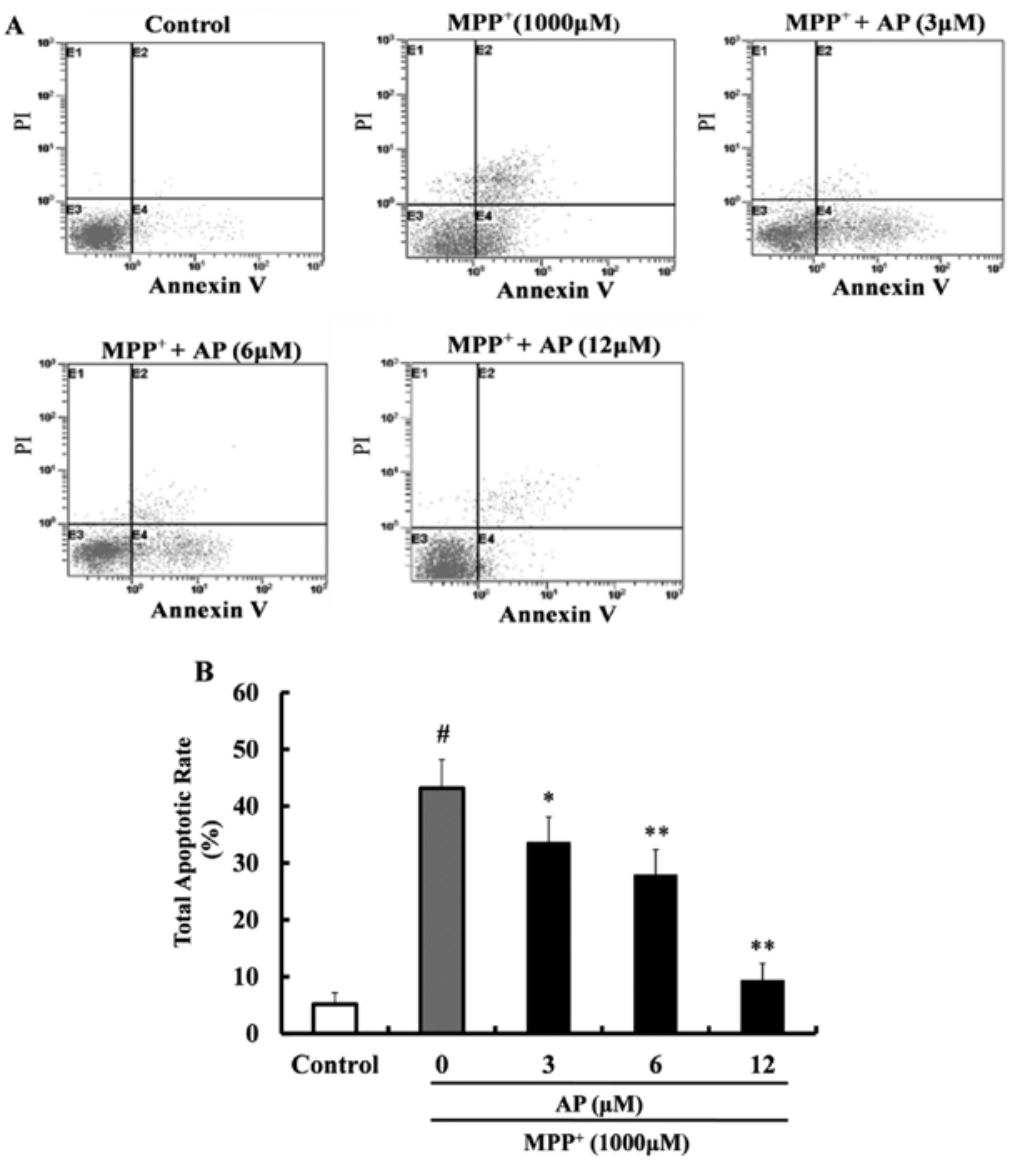

Figure 5. Effect of apigenin (AP) on 1-methyl-4-phenylpyridinium ion (MPP ${ }^{+}$-induced apoptosis in rat pheochromocytoma cells (PC12 cells). (A) Diagram of flow cytometry of double-staining with Annexin V-FITC/propidium iodide (PI). (B) Graphical representation of the total apoptotic rate. Data are presented as the means \pm SEM for 3 independent experiments. ${ }^{*} \mathrm{P}<0.01$ compared with the control cells; ${ }^{*} \mathrm{p}<0.05$ and ${ }^{* *} \mathrm{p}<0.01$ compared with the cells exposed to MPP ${ }^{+}$alone.

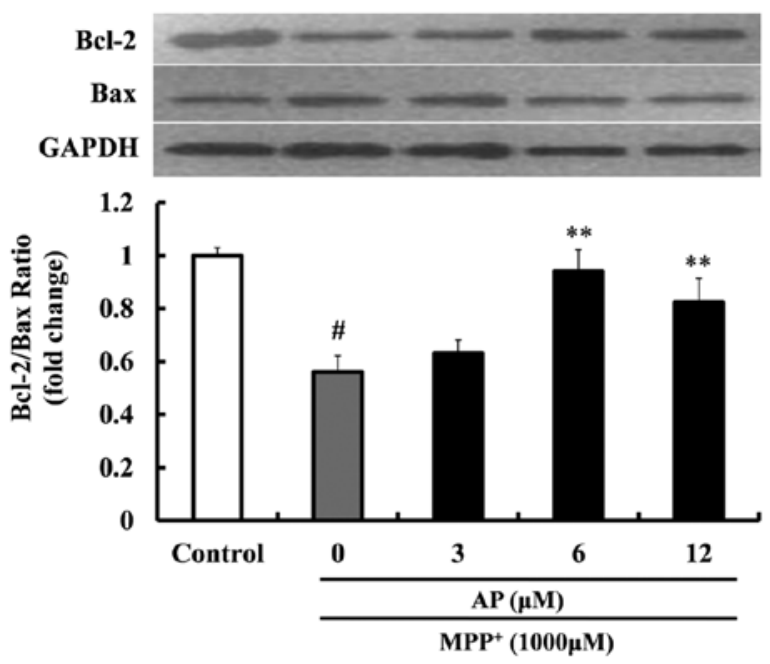

Figure 6. Effect of apigenin (AP) on the expression of Bcl-2 and Bax in 1-methyl-4-phenylpyridinium ion (MPP')-treated rat pheochromocytoma cells (PC12 cells). PC12 cells were pre-treated with or without AP (3-12 $\mu \mathrm{M})$ for $4 \mathrm{~h}$ and then exposed to $\mathrm{MPP}^{+}(1,000 \mu \mathrm{M})$ for $48 \mathrm{~h}$. Data are presented as the means \pm SEM of fold changes relative to the controls $(n=3) .{ }^{\#} \mathrm{P}<0.01$ compared with the control cells; ${ }^{* *}<<0.01$ compared with the cells exposed to $\mathrm{MPP}^{+}$alone.

Effect of AP on the expression of Bcl-2 and Bax in $M P P^{+}$-treated PC12 cells. To elucidate the molecular mechanisms respon- sible for the protective effects exerted by AP against PC12 cell apoptosis induced by $\mathrm{MPP}^{+}$, we measured the ratio of $\mathrm{Bcl}-2 / \mathrm{Bax}$ protein expression. Following exposure to $1,000 \mu \mathrm{M}$ $\mathrm{MPP}^{+}$for $48 \mathrm{~h}$, as shown in Fig. 6, the ratio of Bcl-2/Bax was sharply decreased (1.79-fold decrease relative to control, $\mathrm{p}<0.01)$. However, when the cells were pre-treated with AP at the concentrations of 6 and $12 \mu \mathrm{M}$, the above changes induced by $\mathrm{MPP}^{+}$were significantly mitigated. The ratio of $\mathrm{Bcl}-2 / \mathrm{Bax}$ was significantly increased $(\mathrm{p}<0.01$ and $\mathrm{p}<0.01$, respectively), compared with the cells treated with $\mathrm{MPP}^{+}$alone.

\section{Discussion}

Various pharmacological and surgical treatments have been used in patients with PD; however, some of these have significant adverse effects and most do not halt or retard the degeneration of dopaminergic neurons (28). Thus, in recent years, considerable attention has been paid to the development of neuroprotective drugs from natural origins as a therapeutic strategy for PD (29). Since naturally occurring plant-derived flavonoids have been shown to play a useful role in protecting the central nervous system (15), in this study, we investigated the neuroprotective effects of the three most potent protective natural flavonoids, including AP, GA and GE, using the model of $\mathrm{MPP}^{+}$-induced neurotoxicity in $\mathrm{PC} 12$ cells. Our data suggested that the neuroprotective effects of these natural 
flavonoids varied dramatically, although they are structurally similar. Significant protective effects of AP were observed against $\mathrm{MPP}^{+}$-induced cell death, while GA and GE exerted no protective effects. We conclude that this effect may well be due to the position and number of free phenolic hydroxyl groups (OH groups) in their structures. Free $\mathrm{OH}$ group is a typical reactive functional group, particularly when it is attached to a C-7 or C-4' of flavonoid structure (16). A comparison of the AP structure (4',5,7-trihydroxyflavone) with that of GA (3,5,7-trihydroxyflavone) (4',5-dihydroxy-7-methoxyflavone) and GE shows that the 5-, 7- and 4'-OH substitutions are important. For GE, one $\mathrm{OH}$ group (at the $\mathrm{C}-7$ position) is methoxylated; for GA, a free 4'-OH group is lacking (Fig. 1). Therefore, AP, with three free $\mathrm{OH}$ groups at $\mathrm{C}-5, \mathrm{C}-7$ and $\mathrm{C}-4$ ' positions, exerts significant protective effect against $\mathrm{MPP}^{+}$-induced neurotoxicity in PC12 cells. Our data further suggest that AP ameliorates the $\mathrm{MPP}^{+}$-induced production of ROS, increases the number of viable cells, attenuates the release of $\mathrm{LDH}$, prevents the loss of MMP, reduces the total number of apoptotic cells and elevates the ratio of $\mathrm{Bcl}-2 / \mathrm{Bax}$. Even in the long-term procedure of $\mathrm{MPP}^{+}$-induced cytotoxicity in $\mathrm{PC} 12$ cells, significant neuroprotective effects of AP can be observed.

There is convincing evidence that the overproduction of ROS, which leads to a pro-oxidant state known as oxidative stress, plays an important role in the etiology and/or progression of a number of neurological diseases and is responsible for neurodegeneration $(5,30)$. The excessive production of ROS can cause severe impairment of cellular functions, such as peroxidize membrane lipids, oxidize protein and attack cytoplasmic RNA and mitochondrial DNA (31). Moreover, previous data have demonstrated that ROS are involved in the apoptotic mechanism of $\mathrm{MPP}^{+}$-mediated neurotoxicity and may contribute to the apoptotic processes that are associated with the development of PD (32). In addition, ROS generated by $\mathrm{MPP}^{+}$may be at least partly responsible for the opening of mitochondrial permeability transition pores and the collapse of MMP (33). As mentioned above, our experiment data suggested that treatment with $\mathrm{MPP}^{+}$ resulted in a significant increase in ROS production which was consistent with previous research papers $(14,22)$ and pre-treatment with AP markedly reduced the generation of intracellular ROS. Based on these findings, it can be concluded that AP ameliorates oxidative damage induced by $\mathrm{MPP}^{+}$in $\mathrm{PC} 12$ cells at least partly through the scavenging of ROS.

Mitochondria are well known to be the principal source of intracellular ROS production (5). The production of ROS in the mitochondria is accelerated by ROS themselves, termed ROS-induced ROS release and ROS generation in only small numbers of mitochondria can affect neighboring mitochondria, eventually propagating the ROS surge to the whole cell through this positive feedback loop (6). The overproduction of ROS rapidly causes a decrease in MMP and then this depolarization of MMP results in the release of apoptogenic factors, such as cytochrome $c$ from the intermembrane space to the cytoplasm. Subsequently, cytochrome $c$ and other apoptogenic factors trigger the caspase family and induce cells apoptosis $(5,34)$. In this study, the involvement of the mitochondria in $\mathrm{MPP}^{+}$-induced apoptosis was investigated by evaluating the loss of MMP. Our data indicated that the treatment of the PC12 cells with $\mathrm{MPP}^{+}$markedly reduced MMP, which was detected by $\mathrm{JC}-1$ staining, and the reduction in MMP induced by $\mathrm{MPP}^{+}$ was reversed by pre-treatment with AP. These results strongly suggest that AP stabilizes the $\mathrm{MPP}^{+}$-induced MMP disruption and that this may be attributed to the oxidative stress-reducing action of AP.

In addition, the mitochondrial apoptotic pathway is the best known intrinsic apoptotic pathway (35). Although the precise mechanisms through which the Bcl-2 family acts remain unclear, it has been established that the Bcl-2 family does indeed play a pivotal role in the mitochondrial apoptotic pathway (14). The Bcl-2 family proteins consist of two subgroups according to structural homology: the anti-apoptotic proteins, such as $\mathrm{Bcl}-2$ and the pro-apoptotic proteins, including Bax (36). It is now evident that Bcl-2 or Bax control the mitochondrial permeability transition pores or influence other early mitochondrial perturbations (37). Therefore, Bcl-2 or Bax may facilitate the passage of certain important proteins, such as cytochrome $c$ or other apoptosis-inducing factors that may trigger the activation of a caspase cascade and result in apoptosis. Cell survival in the early phases of the apoptotic cascade depends mostly on the balance between the anti-apoptotic and pro-apoptotic proteins of the Bcl-2 family (38). In this regard, the $\mathrm{Bcl}-2 / \mathrm{Bax}$ ratio may predict the apoptotic fate of the cell better than the absolute concentrations of either molecule alone (39). In the present study, we investigated the effects of AP on the expression levels of Bcl-2 and $\mathrm{Bax}$ in $\mathrm{MPP}^{+}$-treated cells by western blot analysis. Our data indicated that $\mathrm{MPP}^{+}$significantly decreased the ratio of $\mathrm{Bcl}-2 / \mathrm{Bax}$, a result that was consistent with that of previous studies (40). However, pre-treatment with AP increased the expression of Bcl-2, while significantly decreasing the expression of Bax, thus ameliorating the $\mathrm{MPP}^{+}$-induced reduction in the $\mathrm{Bcl}-2 / \mathrm{Bax}$ ratio in $\mathrm{PC} 12$ cells. Therefore, the effects of $\mathrm{AP}$ on $\mathrm{MPP}^{+}$-induced apoptosis may be at least be partially mediated through the regulation of the expression of Bcl-2 and Bax. These results suggest that the neuroprotective effects of AP are associated with the inhibition of apoptosis through the mitochondrial pathway.

In conclusion, the results from our study demonstrate that AP exerts a protective effect against $\mathrm{MPP}^{+}$-induced neurotoxicity in PC12 cells and that the neuroprotective effects of AP are, at least partially mediated through the inhibition of oxidative stress, the stabilization of mitochondrial function and the reduction of neuronal apoptosis via the mitochondrial pathway. To the best of our knowledge, this is the first study to demonstrate that AP rescues neuronal cells from $\mathrm{MPP}^{+}$-induced apoptosis in vitro. The present results suggest that treatment with AP may prove to be an effecive therapeutic approach for neuroprotection in PD. The neuroprotective effects of this compound in PD require further investigation in primary neuronal cultures, as well as in animal models of PD.

\section{Acknowledgements}

This study was supported by grant no. 2011BAI01B01 from the Key Technologies Research and Development Program of China, grant no. 06CXTD004 from the Program for Innovative Research Team of Higher Education of Guangdong Province of China, grant no. 2012A080202002 from the Science and Technology Planning Project of Guangdong Province of China and educational finance grant no. 276 (2014) from the 
Special Funds from Central Finance of China in Support of the Development of Local Colleges and University.

\section{References}

1. de Lau LM and Breteler MM: Epidemiology of Parkinson's disease. Lancet Neurol 5: 525-535, 2006.

2. Henchcliffe $\mathrm{C}$ and Beal MF: Mitochondrial biology and oxidative stress in Parkinson disease pathogenesis. Nat Clin Pract Neurol 4: 600-609, 2008.

3. Kanthasamy A, Jin H, Mehrotra S, Mishra R, Kanthasamy A and Rana A: Novel cell death signaling pathways in neurotoxicity models of dopaminergic degeneration: relevance to oxidative stress and neuroinflammation in Parkinson's disease. Neurotoxicology 31: 555-561, 2010.

4. Winklhofer KF and Haass C: Mitochondrial dysfunction in Parkinson's disease. Biochim Biophys Acta 1802: 29-44, 2010.

5. Yan MH, Wang X and Zhu X: Mitochondrial defects and oxidative stress in Alzheimer disease and Parkinson disease. Free Radic Biol Med 62: 90-101, 2013.

6. Zorov DB, Filburn CR, Klotz LO, Zweier JL and Sollott SJ: Reactive oxygen species (ROS)-induced ROS release: a new phenomenon accompanying induction of the mitochondrial permeability transition in cardiac myocytes. J Exp Med 192: 1001-1014, 2000.

7. Roucou $X$ and Martinou JC: Conformational change of Bax: a question of life or death. Cell Death Differ 8: 875-877, 2001.

8. Tipton KF and Singer TP: Advances in our understanding of the mechanisms of the neurotoxicity of MPTP and related compounds. J Neurochem 61: 1191-1206, 1993.

9. Langston JW and Ballard PA Jr: Parkinson's disease in a chemist working with 1-methyl-4-phenyl-1,2,5,6-tetrahydropyridine. N Engl J Med 309: 310, 1983.

10. Tetrud JW, Langston JW, Garbe PL and Ruttenber AJ: Mild parkinsonism in persons exposed to 1-methyl-4-phenyl-1,2,3,6tetrahydropyridine (MPTP). Neurology 39: 1483-1487, 1989.

11. Greene LA and Tischler AS: Establishment of a noradrenergic clonal line of rat adrenal pheochromocytoma cells which respond to nerve growth factor. Proc Natl Acad Sci USA 73: 2424-2428, 1976.

12. Mao QQ, Ip SP, Ko KM, Tsai SH, Zhao M and Che CT: Peony glycosides protect against corticosterone-induced neurotoxicity in PC12 cells. Cell Mol Neurobiol 29: 643-647, 2009.

13. Jiang B, Zhang H, Bi J and Zhang XL: Neuroprotective activities of catalpol on $\mathrm{MPP}^{+} / \mathrm{MPTP}$-induced neurotoxicity. Neurol Res 30: 639-644, 2008.

14. Zhou J, Sun Y, Zhao X, Deng Z and Pu X: 3-O-demethylswertipunicoside inhibits $\mathrm{MPP}^{+}$-induced oxidative stress and apoptosis in PC12 cells. Brain Res 1508: 53-62, 2013.

15. Schroeter H, Spencer JP, Rice-Evans C and Williams RJ: Flavonoids protect neurons from oxidized low-density-lipoprotein-induced apoptosis involving c-Jun $\mathrm{N}$-terminal kinase (JNK), c-Jun and caspase-3. Biochem J 358: 547-557, 2001.

16. Li S, Chou G, Hseu Y, Yang H, Kwan H and Yu Z: Isolation of anticancer constituents from flos genkwa (Daphne genkwa Sieb.et Zucc.) through bioassay-guided procedures. Chem Cent J 7: $159,2013$.

17. Jacobson KA, Moro S, Manthey JA, West PL and Ji XD: Interactions of flavones and other phytochemicals with adenosine receptors. Adv Exp Med Biol 505: 163-171, 2002.

18. Jaganathan SK and Mandal MJ: Antiproliferative effects of honey and of its polyphenols: a review. J Biomed Biotechnol 2009: 830616, 2009.

19. Shukla S and Gupta S: Apigenin: a promising molecule for cancer prevention. Pharm Res 27: 962-978, 2010.

20. Liu R, Zhang T, Yang H, Lan X, Ying J and Du G: The flavonoid apigenin protects brain neurovascular coupling against amyloid- $\beta_{25-35}$-induced toxicity in mice. J Alzheimers Dis 24 : 85-100, 2011.

21. Zhao L, Wang JL, Wang YR and Fa XZ: Apigenin attenuates copper-mediated $\beta$-amyloid neurotoxicity through antioxidation, mitochondrion protection and MAPK signal inactivation in an AD cell model. Brain Res 1492: 33-45, 2013.
22. Wruck CJ, Claussen M, Fuhrmann G, Römer L, Schulz A, Pufe T, Waetzig V, Peipp M, Herdegen T and Götz ME: Luteolin protects rat $\mathrm{PC} 12$ and $\mathrm{C} 6$ cells against $\mathrm{MPP}^{+}$induced toxicity via an ERK dependent Keap1-Nrf2-ARE pathway. J Neural Transm Suppl: 57-67, 2007.

23. Zhang ZT, Cao XB, Xiong N, Wang HC, Huang JS, Sun SG and Wang T: Morin exerts neuroprotective actions in Parkinson disease models in vitro and in vivo. Acta Pharmacol Sin 31: 900-906, 2010

24. Zhang K, Ma Z, Wang J, Xie A and Xie J: Myricetin attenuated $\mathrm{MPP}^{+}$-induced cytotoxicity by anti-oxidation and inhibition of MKK4 and JNK activation in MES23.5 cells. Neuropharmacology 61: 329-335, 2011.

25. Kong SZ, Xian YF, Ip SP, Lai XP, Shi XG, Lin ZX and Su ZR: Protective effects of hydroxysafflor yellow A on $\beta$-amyloid-induced neurotoxicity in PC12 cells. Neurochem Res 38: 951-960, 2013.

26. Wang D, Wong HK, Feng YB and Zhang ZJ: Paeoniflorin, a natural neuroprotective agent, modulates multiple anti-apoptotic and pro-apoptotic pathways in differentiated PC12 cells. Cell Mol Neurobiol 33: 521-529, 2013.

27. Liu XH, Pan LL, Chen PF and Zhu YZ: Leonurine improves ischemia-induced myocardial injury through antioxidative activity. Phytomedicine 17: 753-759, 2010.

28. Toulouse A and Sullivan AM: Progress in Parkinson's diseasewhere do we stand? Prog Neurobiol 85: 376-392, 2008.

29. Kwon IH, Choi HS, Shin KS, Lee BK, Lee CK, Hwang BY, Lim SC and Lee MK: Effects of berberine on 6-hydroxydopamine-induced neurotoxicity in PC12 cells and a rat model of Parkinson's disease. Neurosci Lett 486: 29-33, 2010.

30. Federico A, Cardaioli E, Da Pozzo P, Formichi P, Gallus GN and Radi E: Mitochondria, oxidative stress and neurodegeneration. J Neurol Sci 322: 254-262, 2012.

31. Uttara B, Singh AV,Zamboni P and Mahajan RT: Oxidative stress and neurodegenerative diseases: a review of upstream and downstream antioxidant therapeutic options. Curr Neuropharmacol 7: 65-74, 2009.

32. Lu XL, Yao XL, Liu Z, Zhang H, Li W, Li Z, Wang GL, Pang J, Lin Y, Xu Z, et al: Protective effects of xyloketal B against $\mathrm{MPP}^{+}$-induced neurotoxicity in Caenorhabditis elegans and PC12 cells. Brain Res 1332: 110-119, 2010.

33. Cassarino DS, Parks JK, Parker WD Jr and Bennett JP Jr: The parkinsonian neurotoxin $\mathrm{MPP}^{+}$opens the mitochondrial permeability transition pore and releases cytochrome $c$ in isolated mitochondria via an oxidative mechanism. Biochim Biophys Acta 1453: 49-62, 1999.

34. Ling YH, Liebes L, Zou Y and Perez-Soler R: Reactive oxygen species generation and mitochondrial dysfunction in the apoptotic response to bortezomib, a novel proteasome inhibitor, in human $\mathrm{H} 460$ non-small cell lung cancer cells. J Biol Chem 278: 33714-33723, 2003.

35. Muñoz-Pinedo C: Signaling pathways that regulate life and cell death: evolution of apoptosis in the context of self-defense. Adv Exp Med Biol 738: 124-143, 2012.

36. Ghibelli L and Diederich M: Multistep and multitask Bax activation. Mitochondrion 10: 604-613, 2010.

37. Martinou JC and Youle RJ: Mitochondria in apoptosis: Bcl-2 family members and mitochondrial dynamics. Dev Cell 21: 92-101, 2011.

38. Chen Q and Lesnefsky EJ: Blockade of electron transport during ischemia preserves bcl-2 and inhibits opening of the mitochondrial permeability transition pore. FEBS Lett 585: 921-926, 2011.

39. Schelman WR, Andres RD, Sipe KJ,Kang Eand Weyhenmeyer JA: Glutamate mediates cell death and increases the Bax to Bcl-2 ratio in a differentiated neuronal cell line. Brain Res Mol Brain Res 128: 160-169, 2004.

40. Selvaraj S, Watt JA and Singh BB: TRPC1 inhibits apoptotic cell degeneration induced by dopaminergic neurotoxin $\mathrm{MPTP} / \mathrm{MPP}^{+}$. Cell Calcium 46: 209-218, 2009. 